\title{
Comparison of different regimens of estradiol benzoate treatments followed by long-acting progesterone to prepare noncycling mares as embryo recipients
}

\author{
E.S.M. Silva ${ }^{a, *}$, J.F. Roser ${ }^{b}$, A.R.C. Gomes ${ }^{a}$, S.C. Fritsch ${ }^{\text {a }}$, J.C.F. Pantoja ${ }^{c}$, \\ J.P. Oliveira-Filho ${ }^{\mathrm{d}}$, C. Meira ${ }^{\mathrm{a}, *}$

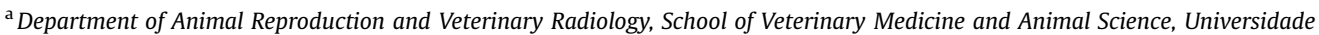 \\ Estadual Paulista, Botucatu, São Paulo, Brazil \\ ${ }^{\mathrm{b}}$ Department of Animal Science, University of California, Davis, California, USA \\ ${ }^{\mathrm{c}}$ Department of Veterinary Hygiene and Public Health, School of Veterinary Medicine and Animal Science, Universidade Estadual \\ Paulista, Botucatu, São Paulo, Brazil \\ ${ }^{\mathrm{d}}$ Department of Veterinary Clinical Science, School of Veterinary Medicine and Animal Science, Universidade Estadual Paulista, \\ Botucatu, São Paulo, Brazil
}

\section{A R T I C L E I N F O}

\section{Article history:}

Received 27 January 2016

Received in revised form 21 May 2016

Accepted 27 May 2016

\section{Keywords:}

Equine embryo transfer

Recipient mares

Hormonal protocols

Estrogen

Progesterone

\begin{abstract}
A B S T R A C T
The present study evaluated the influence of different regimens of estradiol benzoate (EB) treatments followed by a single dose of long-acting progesterone (LA P4) on plasma estrogen and P4 concentrations in noncyclic mares prepared as embryo recipients. Twenty-one anestrous mares were distributed into three groups ( $\mathrm{n}=7$ mares per group), according to the EB dose received (single dose of $2.5 \mathrm{mg}$, total of $5 \mathrm{mg}$ in decreasing doses, and total of $10 \mathrm{mg}$ in decreasing doses), which was followed by a single administration of $1500 \mathrm{mg}$ of LA P4 in all groups. Mares were reevaluated during the ovulatory phase and seven of them became part of the cyclic nontreated control group. Ultrasonography was performed to monitor endometrial edema, and blood samples were collected to measure estradiol (E2), estrogen conjugate (EC), and P4 by RIA. Maximum uterine edema was achieved 24 hours after administration of EB in all treated groups. Maximum E2 concentrations were observed 24 hours after the first EB injection in treated groups and there were no differences $(P>0.05)$ among treatments. Maximum EC concentration was observed 24 hours after the single EB injection in the $2.5-\mathrm{mg}$ group, whereas in the 5 - and 10 -mg groups EC peaks were observed 48 hours after the first EB administration. Maximum P4 concentrations were detected 24 hours after LA P4 injection, although higher P4 concentrations were observed in the group treated with $2.5 \mathrm{mg}$ of EB than in that treated with $10 \mathrm{mg}$ of $\mathrm{EB}(\mathrm{P}<0.05)$. Because $\mathrm{P} 4$ concentrations were reduced after administration of high doses of EB, we also measured $17 \alpha$-hydroxyprogesterone (17-OH-P) to test the hypothesis that high concentrations of EB would accelerate the conversion of P4 to 17-OH-P. However, 17-OH-P concentrations paralleled P4 profile in all groups, irrespective of EB doses. In summary, the three EB treatment regimens induced similar E2 peaks, although the observation of EC peaks 24 hours after E2 peaks in the 5- and 10-mg groups indicate that an excess of E2 was given, which was converted into EC to be inactivated. Administration of $10 \mathrm{mg}$ of EB reduced P4 concentrations 24 hours after LA P4 was given. We demonstrated that the mechanism by which this reduction occurred was not by
\end{abstract}

\footnotetext{
* Corresponding author. Tel.: +55 14 3880-2119; fax: +55 14 38802122.

E-mail addresses: elisa_santanna@yahoo.com.br(E.S.M. Silva), meira@ fmvz.unesp.br (C. Meira).
} 
an increase in $\mathrm{P} 4$ metabolism to $17 \alpha-\mathrm{OH}-\mathrm{P}$. In conclusion, the use of $2.5 \mathrm{mg}$ of EB followed by $1500 \mathrm{mg}$ of LA P4 appears to be a more appropriate regimen to treat noncyclic mares, although additional studies are needed to verify embryo survival with this treatment dose.

(c) 2016 Elsevier Inc. All rights reserved.

\section{Introduction}

Equine embryo transfer (ET) is a worldwide technique in which the highest number of transferred embryos per year is found in Brazil, Argentina, and the United States [1]. However, a major limiting factor in the ET programs is the reduced number and quality of recipient mares during the breeding season and especially during the early spring transitional period [2]. For some horse breed associations in the southern and northern hemisphere, the use of recipient mares early in the year outside the normal breeding season (spring through early fall) is very desirable [3] because there is economic pressure for foals to be born early in the foaling season to enhance their athletic performance.

To increase the availability of recipient mares in ET programs, exogenous estrogen and progesterone (P4) treatments are usually administered to noncyclic mares [2-6]. Currently, noncyclic recipient mares often receive estradiol benzoate (EB) $[2,7,8]$, an ester of the natural estrogen $17 \beta$ estradiol (E2) with an approximate half-life of 3 days [9]. After the observation of endometrial edema, long-acting progesterone (LA P4; half-life of 7 days) is administered 3 to 8 days before ET $[3,10]$, or altrenogest is given during 4 to 6 days before transfer [2,11], to achieve an appropriate progesterone concentration ( $\geq 2.5 \mathrm{ng} / \mathrm{mL}$ ) [6] at the time of ET. These hormones (natural or synthetic) induce similar uterine changes to those which occur in cyclic mares [12], such as endometrial edema caused by estradiol followed by increased uterine tone and stimulus to histotrophic secretion as a result of exogenous progestin treatment [13]. The hormonal changes prepare the uterus for a possible pregnancy.

Although protocols for exogenous P4 have already been described regarding suitable P4 concentrations for pregnancy maintenance [14], EB administration is empirical with different reports of dose and administration frequencies for preparing noncyclic recipient mares such as a single dose of $2.5 \mathrm{mg}[2,11]$ and decreasing doses of $5[15]$ or $10 \mathrm{mg}[7,8]$.

To our knowledge, there are no studies comparing EB regimens to select the treatment that causes endometrial edema and produce similar estrogen concentrations to those found in cyclic mares during estrus. The knowledge of an exogenous estrogen protocol that is more compatible with endogenous estrogen concentrations found in cyclic mares would optimize the hormone regimen in noncyclic embryo recipient mares. Therefore, the objective of this study was to evaluate different regimens of EB followed by a single dose of LA P4 on plasma estrogen and P4 concentrations in noncyclic mares and evaluate the degree of endometrial edema after treatments.

\section{Material and methods}

\subsection{Animals and experimental groups}

Twenty-one cross-bred mares from 5 to 15 years of age, weighing between 350 and $450 \mathrm{~kg}$, were used in the study.
Mares were maintained on coast-cross hay (Cynodon dactylon) with water and trace-mineralized salt ad libitum. The experiment was conducted from June to December in Botucatu, São Paulo, Brazil (latitude 22 53'09' and longitude $48^{\circ} 26^{\prime} 42^{\prime \prime}$ ). In the southern hemisphere, June through early September are winter months, and late September through early December is the spring season. Animal procedures were approved by the Ethics Committee on Animal Use at the School of Veterinary Medicine and Animal Science, Universidade Estadual Paulista (CEUA-200/ 2014).

Data were collected from anestrous mares that were used later in the season for data collection during the cyclic phase. Anestrous mares were those showing ovarian follicles less than $20 \mathrm{~mm}$ in diameter, absence of a CL, and P4 concentrations $<1 \mathrm{ng} / \mathrm{mL}$ on three evaluations at 7-day intervals. Data from all anestrous mares were collected in July and August, under short-day photoperiod. Cyclic mares were those showing regular estrous cycles with ovulatory follicles and presence of a CL at least once in 21 days. Data from cyclic mares were collected between October and December, under increasing photoperiod.

The 21 anestrous mares selected to the experiment were randomly distributed into three groups ( $\mathrm{n}=7$ mares per group), according to EB regimen followed by the same dose of LA P4: $2.5 \mathrm{mg}$ EB + LA P4, $5 \mathrm{mg}$ EB + LA P4, and $10 \mathrm{mg}$ EB + LA P4. After treatments, the anestrous mares were monitored until cyclic activity was detected. Once in the cyclic reproductive phase, seven mares were randomly chosen out of the initial 21 to be part of the control group. Data collection in the control group started from the third estrous cycle of the breeding season. A cyclic nontreated control group was used to compare artificially induced reproductive phases to physiological reproductive phases.

\subsection{Hormone treatments}

Mares from the group $10 \mathrm{mg}$ EB + LA P4 received $10 \mathrm{mg}$ of EB (Estrogin, im) in decreasing doses (5, 3, and $2 \mathrm{mg}$ on consecutive days), and 24 hours after the last EB administration, $1500 \mathrm{mg}$ of LA P4 (Sincrogest Injetável, im) was given (Fig. 1A). The group $5 \mathrm{mg}$ EB + LA P4 received $5 \mathrm{mg}$ of $\mathrm{EB}$ in decreasing doses ( 3 and $2 \mathrm{mg}$ on consecutive days), and 24 hours after the last EB administration, $1500 \mathrm{mg}$ of LA P4 was given (Fig. 1B). The group $2.5 \mathrm{mg}$ EB + LA P4 received a single $2.5-\mathrm{mg}$ dose of $\mathrm{EB}$, and 48 hours after its administration, mares were treated with $1500 \mathrm{mg}$ of LA P4 (Fig. 1C). Control group consisted of cyclic mares that did not receive EB and LA P4 treatments. During the cyclic phase of the control group mares, ovulation induction was performed using 1500 IU of hCG (Vetecor, iv) after detection of a $35-\mathrm{mm}$ follicle or more and uterine edema to synchronize evaluation days between natural and artificial cycles (Fig. 1D). 
A

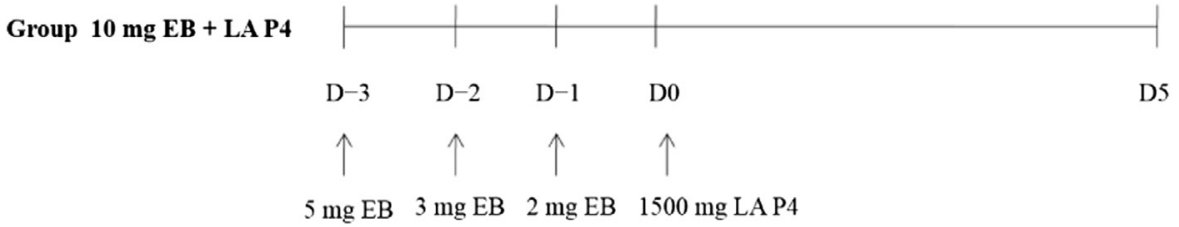

B

Group $5 \mathrm{mg} \mathrm{EB}+$ LA P4

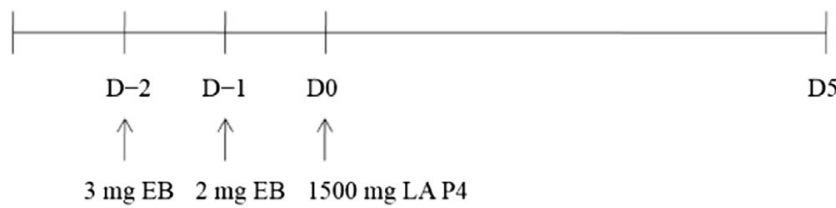

C

Group $2.5 \mathrm{mg}$ EB + LA P4

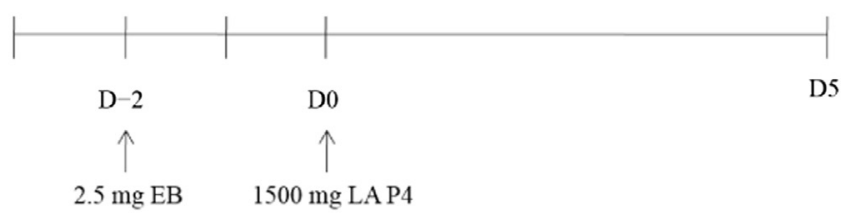

D Control group
(cyclic mares)

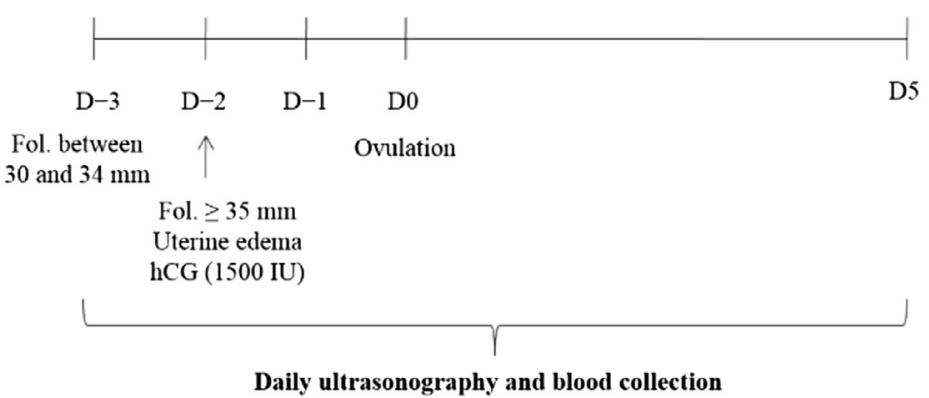

Fig. 1. Representative scheme of the EB followed by LA P4 treatments administered to groups: (A) 10 mg EB + LA P4, (B) 5 mg EB + LA P4, and (C) 2.5 mg EB + LA P4. During the cyclic phase of the control group mares, ovulation induction was performed after detection of a 35-mm follicle or less and uterine edema (D) to synchronize evaluation days between natural and artificial cycles. Daily ultrasound examinations and blood collections were performed in all groups. D, day; EB, estradiol benzoate; LA P4, long-acting progesterone.

\subsection{Ultrasound examinations}

Mares were examined with B-mode ultrasonography (MindrayDP-3300Vet, Shenzhen, China) to monitor their reproductive status during anestrus and cyclic phase. Moreover, when data collection was initiated, ultrasonography was performed daily immediately before the first EB administration until Day 5 after LA P4 administration (Day 0 ) in treated groups and from the detection of a $30-\mathrm{mm}$ follicle until Day 5 after ovulation (Day 0) in control group. During this period, endometrial edema was quantified and scored as 0 (no edema), 1 (slight edema), 2 (moderate edema), or 3 (high edema) [16].

\subsection{Blood collection}

Blood samples were collected through jugular venipuncture into heparinized tubes every 24 hours immediately before the first EB administration until Day 5 after LA
P4 administration in treated groups and from the detection of a $30-\mathrm{mm}$ follicle until Day 5 after ovulation in control group. Plasma samples were centrifuged and stored at $-20^{\circ} \mathrm{C}$ until assayed for E2, estrogen conjugate (EC), and P4 by RIA.

\subsection{Radioimmunoassay}

\subsubsection{Estradiol radioimmunoassay}

The concentrations of plasma E2 were measured by a validated RIA [17]. The primary antibody was a sheep antiestradiol-17 $\beta$-6-BSA (\#244, Niswender; Colorado State University, Fort Collins, CO, USA) used at a 1/60,000 dilution, and the trace was ${ }^{3} \mathrm{H}$-estradiol $\left(1,2,6,7-{ }^{3} \mathrm{H}-\mathrm{E} 2\right.$, NET-317, specific activity 70-115 Ci/mmol; Perkin Elmer Life Science, Boston, MA, USA). Standards (E950; Steraloids, Wilton, NH, USA) ranged from 6.25 to $500 \mathrm{pg} / \mathrm{mL}$. Two hundred microliters of plasma or control samples were extracted with $2 \mathrm{~mL}$ of fresh reagent grade anhydrous ethyl 
ether (EMD-Millipore, Gibbstown, NJ, USA) and reconstituted with $300 \mu \mathrm{L}$ of PBS with $0.1 \%$ porcine skin gelatin (PBS-G; Sigma, St Louis, MO, USA). The sensitivity of the assay was $8 \mathrm{pg} / \mathrm{mL}$, and the intra- and inter-assay coefficients of variation were 3.9\% $(n=6)$ and $8.9 \%$ $(n=8)$, respectively. The extraction efficiency was $88 \%$.

\subsubsection{Estrogen conjugate RIA}

The concentrations of plasma EC were measured by a validated RIA [18]. The primary antibody was a rabbit antiestrone-3-glucuronide (R-583, C.J. Munro; Clinical Endocrinology Laboratory, University of California, Davis, CA, USA) used at a 1/12,000 dilution, and the trace was estrone sulfate $\left(6,7{ }^{3} \mathrm{H}(\mathrm{N})\right.$, NET-203; Perkin Elmer Life Science). Estrone sulfate was also used as standards (E0251; SigmaAldrich, St Louis, MO, USA), ranging from 0.05 to $12.5 \mathrm{ng} /$ $\mathrm{mL}$. Tris/gel was added to $50 \mu \mathrm{L}$ of plasma or control samples to bring volume up to $300 \mu \mathrm{L}$.

When using estrone-3-sulfate as the standard (100\%), the antibody cross-reacted with estrone (200\%), estradiol$17 \beta$ (100\%), equilin (50\%), estrone-3-glucuronide (38\%), estradiol-3-sulfate (21\%), estradiol-3-glucuronide (6.8\%), and cross-reaction was less than $0.5 \%$ with all the nonestrogenic steroids tested [18]. The sensitivity of the assay was $0.1 \mathrm{ng} / \mathrm{mL}$, and the intra- and inter-assay coefficients of variation were $3.0 \%(n=6)$ and $7.3 \%(n=4)$, respectively.

\subsubsection{Progesterone and $17 \alpha$-hydroxyprogesterone RIAs}

Plasma P4 concentrations were measured using a commercial kit (Immunotech Beckman Coulter-Brea, CA, USA) according to manufacturer's recommendations. Measurements were performed in three assays, and the antiserum was specific for P4, with minimal sensitivity of $0.05 \mathrm{ng} / \mathrm{mL}$. The antiserum presented low cross-reactivity to other steroid hormones, as follows: $5 \alpha$-pregnanedione (15.02\%), 5 $\beta$-pregnanedione (8.12\%), 6 $\beta$-hydroxiprogesterone $(5.1 \%)$ corticosterone (4.07\%), 11-desoxycorticosterone (2.56\%), 16 $\alpha$-hydroxiprogesterone (1.82\%), and $17 \alpha-$ hydroxiprogesterone $(1.15 \%)$. The intra- and interassay coefficients of variation were $12.0 \%(n=6)$ and $12.6 \%(n=3)$, respectively.

Because P4 concentrations were reduced after the administration of higher doses of EB, we hypothesized that high estrogen concentrations could be accelerating P4 metabolism. In this regard, we quantified $17 \alpha$-hydroxyprogesterone (17-OH-P) plasma concentrations starting from Day 0 immediately before LA P4 administration or on ovulation day in treated and control groups, respectively. Concentrations of 17-OH-P were also measured using a commercial kit (ImmuChem 17a-hydroxyprogesterone CT RIA kit; MP Biomedicals, Orangeburg, NY, USA) according to manufacturer's recommendations. Measurements were performed in two assays, and the antiserum was specific for 17-OH-P. Minimal sensitivity was $0.1 \mathrm{ng} / \mathrm{mL}$. The intra- and inter-assay coefficients of variation were $4.3 \%(n=6)$ and $12.5 \%(\mathrm{n}=2)$, respectively.

\subsection{Statistical analysis}

Descriptive statistics (measures of central tendency and dispersion) were carried out to characterize the study sample. All response variables were not normally distributed and were log transformed for analysis to achieve normality. Data were presented as geometric means with confidence intervals to show values in the original scale. A repeated measures model [19] was constructed with PROC MIXED [20] to compare the mean E2, EC, P4, and 17-OH-P concentrations among collection days and treatments. The autoregressive covariance structure provided the best fit to the data and was used to model the correlation between repeated observations within the same mare. Statistical significance was defined as $\mathrm{P}<0.05$.

\section{Results}

\subsection{Ultrasound examinations}

The median scores of uterine edema found during treatments with EB and LA P4 and the edema scores found in the control group are shown in Table 1. A lack of uterine edema was observed before treatments. After EB injection, high uterine edema was achieved 24 hours after administration in all treated groups, remaining high until LA P4 injection. After LA P4 administration, reduction in the edema scores were observed, where the 2.5-mg EB group presented slight edema from Day 1 onward, the 5-mg EB group showed slight to moderate level from Day 3 onward, and the 10-mg EB group exhibited moderate level from Day 2 . In the control group, high edema was observed 3 and 2 days before ovulation, after which a gradual decrease to a slight level was detected on Day 1 after ovulation. On Day 5, a slight increase in the edema (slight to moderate level) was observed in the control group.

\subsection{Plasma concentrations of estradiol and EC}

Maximum concentrations of E2 were observed 24 hours after the single or first EB injection in treated groups, and there were no differences $(P>0.05)$ among treatments (Fig. 2A-C) despite the different doses that were initially given. In the control group, higher concentrations of E2 were observed on $\mathrm{D}-2$ (Fig. 2D) and there were no

\section{Table 1}

Median scores of uterine edema found in noncyclic mares $(n=7$ per group) after EB treatment using a single dose of $2.5 \mathrm{mg}$ on $\mathrm{D}-2$, a total of $5 \mathrm{mg}$ in decreasing doses ( 3 and $2 \mathrm{mg}$ on consecutive days, D-2 and D-1, respectively), and a total of $10 \mathrm{mg}$ in decreasing doses (5, 3 and $2 \mathrm{mg}$ on consecutive days, $\mathrm{D}-3, \mathrm{D}-2$, and $\mathrm{D}-1$, respectively), followed by treatment with $1500 \mathrm{mg}$ of LA P4 on Day 0.

\begin{tabular}{llllllllll}
\hline Groups & \multicolumn{1}{l}{ Uterine edema } \\
\cline { 2 - 9 } & $\begin{array}{l}\text { Days relative to progesterone injection or } \\
\text { ovulation (D0) }\end{array}$ \\
\cline { 2 - 10 } & $\mathrm{D}-3$ & $\mathrm{D}-2$ & $\mathrm{D}-1$ & $\mathrm{D} 0$ & $\mathrm{D} 1$ & $\mathrm{D} 2$ & $\mathrm{D} 3$ & $\mathrm{D} 4$ & $\mathrm{D} 5$ \\
\hline $2.5 \mathrm{mg}$ EB + LA P4 & - & $0^{\mathrm{a}}$ & 3 & 3 & 1 & 1 & 1 & 1 & 1 \\
$5 \mathrm{mg} \mathrm{EB}+$ LA P4 & - & $0^{\mathrm{a}}$ & 3 & 3 & 2.5 & 2 & 1.5 & 1.5 & 1.5 \\
$10 \mathrm{mg}$ EB + LA P4 & $0^{\mathrm{a}}$ & 3 & 3 & 3 & 2.5 & 2 & 2 & 2 & 2 \\
Control & 3 & 3 & 2 & 1.5 & 1 & 1 & 1 & 1 & 1.5 \\
\hline
\end{tabular}

The median scores for cyclic mares (control group) at the corresponding days to treated mares are shown.

Abbreviations: D, day; EB, estradiol benzoate; LA, long acting.

${ }^{\text {a }}$ Uterine edema immediately before EB administration. 

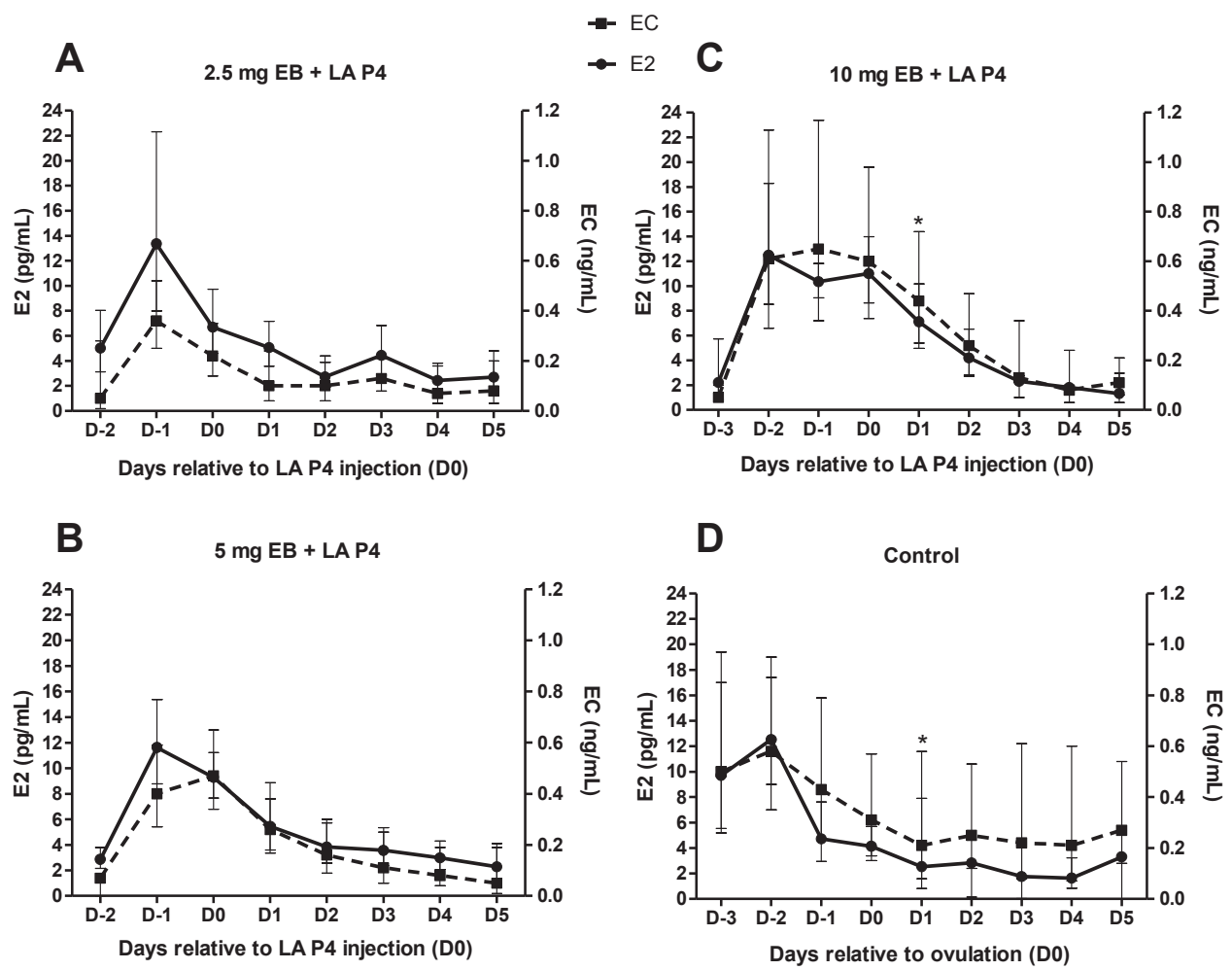

Fig. 2. $\mathrm{E} 2$ and $\mathrm{EC}$ concentrations (geometric means with confidence intervals) in (A) noncyclic mares treated with a single dose of 2.5 of EB on D-2; (B) total of $5 \mathrm{mg}$ of EB in decreasing doses for two consecutive days starting from D-2; (C) total of $10 \mathrm{mg}$ of EB in decreasing doses for three consecutive days starting from D-3. The administration of $1500 \mathrm{mg}$ of LA P4 on Day 0 was performed in all treated groups. (D) Concentrations of E2 and EC in nontreated cyclic mares (control group), where Day 0 was considered as the day of ovulation. Asterisks within days between groups indicate $\mathrm{P}<0.05$. EC, estrogen conjugate; E2, estradiol; LA P4, long-acting progesterone.

differences $(\mathrm{P}>0.05)$ compared with E2 maximum concentrations of the treated groups. When E2 concentrations were compared after LA P4 injection (from Day 1 onward) between groups, statistical difference was only detected on Day 1 between the $10-\mathrm{mg}$ EB and control groups $(\mathrm{P}<0.05$; Fig. 2C, D).

Maximum concentrations of EC were observed 24 hours after the single EB injection in the 2.5-mg group (Fig. 2A), whereas in the 5- and 10-mg groups higher concentrations were observed 48 hours after the first EB administration (or 24 hours after the second injection; Fig. 2B, C). After the peak, concentrations decreased to minimal sensitivity levels $(0.1 \mathrm{ng} / \mathrm{mL}$ ) on Day 1 in the 2.5-mg group (Fig. 2A) and on Day 4 in the 5- and 10-mg EB group (Fig. 2B, C). EC peak was observed on $\mathrm{D}-2$ in the cyclic group and thereafter decreased continuously until Day 1 , remaining relatively constant until Day 5 (Fig. 2D). Differences were not observed $(P>0.05)$ when maximum concentrations of EC were compared among treated groups and between treated and control groups. After LA P4 injection, there were no differences in EC concentrations between groups $(P>0.05)$.

\subsection{Plasma concentrations of progesterone and $17-\mathrm{OH}-\mathrm{P}$}

Maximum concentrations of P4 were observed 24 hours after injection of $1500 \mathrm{mg}$ of LA P4 in treated groups
(Fig. 3A). Despite the same dose of LA P4 given, different P4 concentrations were detected between groups treated with different EB concentrations. Concentration of P4 was higher on Day 1 (24 hours after P4 injection) in the group treated with $2.5 \mathrm{mg}$ of EB than in groups treated with 5 or $10 \mathrm{mg}$ of $\mathrm{EB}$, although statistical difference was only detected $(\mathrm{P}<0.05)$ when the 2.5 - and $10-\mathrm{mg}$ EB groups were compared. There was no difference $(P>0.05)$ on Day 1 between the 5- and 10-mg EB groups (Fig. 3A).

Concentrations of $\mathrm{P} 4$ showed a sharp decrease on Day 2 after LA P4 injection, followed by a less pronounced decrease until Day 5 in the treated groups. There were no statistical differences between treated groups from Day 2 onward (Fig. 3A). In the control group, concentrations of P4 were low before ovulation and started to increase from Day 1 , increasing gradually until Day 5 . Concentrations of P4 were significantly lower $(P<0.05)$ in the cyclic group on Day 1 and significantly higher on Day 5 compared with the treated groups $(\mathrm{P}<0.05$; Fig. $3 \mathrm{~A})$.

The 17-OH-P concentrations paralleled the $\mathrm{P} 4$ profile in both treated and control groups. There appeared to be an increase 24 hours after LA P4 injection and gradual decrease on the subsequent days. In the control group, the P4 metabolite concentration increased gradually until Day 5 . When the hormone concentrations were compared between groups, higher values were observed in the control group compared with the $10-\mathrm{mg}$ EB group $(\mathrm{P}<0.05)$ 


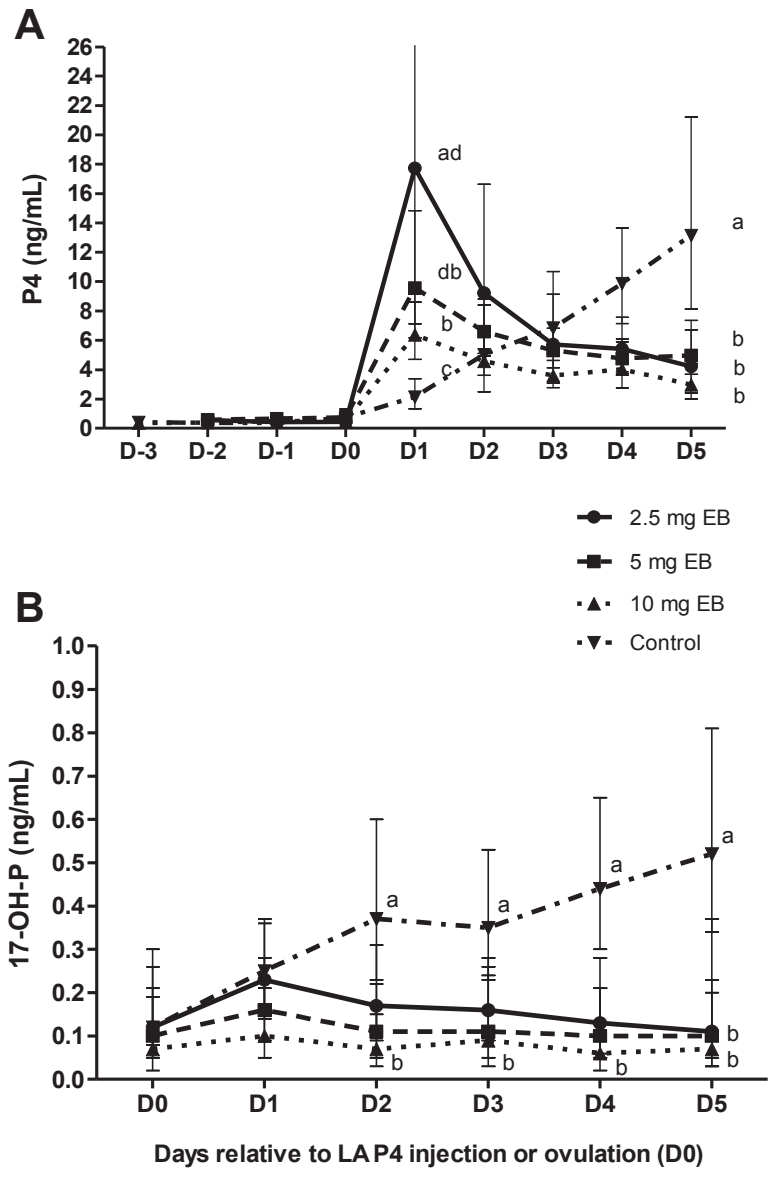

Fig. 3. $\mathrm{P} 4$ and 17-OH-P concentrations (geometric means with confidence intervals) in the control and noncyclic treated groups. (A) P4 profile in the noncyclic groups treated with a single dose of 2.5 of EB on D-2; total of $5 \mathrm{mg}$ of EB in decreasing doses starting from $\mathrm{D}-2$ or total of $10 \mathrm{mg}$ of EB in decreasing doses starting from D-3, followed by the injection of $1500 \mathrm{mg}$ of LA P4 on Day 0 ; as well as $\mathrm{P} 4$ concentrations of the control group (cyclic mares) 3 days before ovulation until Day 5. (B) Concentrations of 17-OH-P in the noncyclic treated and control groups from days 0 to 5 . Different letters within the same day between groups indicate $\mathrm{P}<0.05$. EB, estradiol benzoate; 17-OH-P, $17 \alpha$-hydroxyprogesterone; LA P4, long-acting progesterone.

starting from Day 2 onward and compared with the 5-mg EB group on Day 5 (Fig. 3B).

\section{Discussion}

In view of the fact that recipient mares are key factors for the success of ET programs and that cyclic recipients are not always available, the use of noncyclic mares as embryo recipients has gained more interest. However, the administration of hormone protocols to noncyclic recipients has not been completely investigated, especially the use of estrogen. In the present study, we evaluated and compared plasma E2 and P4 concentrations after treating noncyclic mares with different regimens of EB followed by a single dose of LA P4. Our focus was to evaluate which protocol would produce similar uterine edema and plasma estrogen concentrations to those observed in cyclic mares. A cyclic nontreated control group was important to include to observe the natural endogenous estradiol and progesterone concentrations during late estrus and early diestrus.

Administration of a single dose of $2.5 \mathrm{mg}$ EB and the first doses of 3 and $5 \mathrm{mg}$ of EB from the 5- and 10-mg EB group, respectively, were effective at promoting high endometrial edema 24 hours after injection. High edema was also observed in the control group, 3 and 2 days before ovulation which is in agreement with previous reports on cyclic mares [21]. Moreover, edema remained high in all treated groups, regardless of additional EB injections, until LA P4 administration. Uterine edema accompanied estrogen profile in the control group, whereas in treated groups, mainly in the ones treated with higher EB concentrations, decrease in estrogen concentrations did not necessarily decrease uterine edema to the same extent. It is likely that the higher EB concentrations given to the 5- and 10-mg EB group continued to stimulate uterine edema even after P4 administration and the decline of plasma estrogen concentrations.

Ultrasonic uterine echotexture studies have revealed the presence of a slight increase in edema in early diestrus during the first half of the ovulatory season but not during the second half [22]. This phenomenon may reflect follicular growth that occurs in some mares in early diestrus or estrogen production by the developing corpus luteum [18]. Accordingly, in the present study, a slight rise in edema was observed on Day 5 after ovulation in the control group. However, we do not have accurate information on follicular activity after ovulation because our focus was on the uterus. Here, the reason for the slight rise in uterine edema on Day 5 after ovulation is inconclusive.

It is generally considered that measuring the active form of estrogen, E2, provides the best information in terms of hormone signal delivered to the target cell. However, because circulating E2 concentrations are low in some animals, the accuracy of this method is sometimes limited [18]. In the present study, only concentrations after EB injections were above the E2 assay sensitivity. On the other hand, plasma EC concentrations are 100-fold higher than plasma E2 concentrations [18]. In addition, it has been reported that the increase of plasma-conjugated estrogens parallels plasma E2, and thus, the same physiological information can be obtained by EC (estrone sulfate) analysis in cyclic mares [18]. For this reason, we also provided the EC profile in treated and control groups.

As observed in the control group, EC profile paralleled E2 profile in the 2.5-mg EB group, where maximum EC and E2 concentrations were detected 24 hours after EB administration followed by a decrease of both hormone concentrations. However, EC peaks in the 5- and 10-mg EB groups were observed 24 hours after E2 peak. In women, it has been described that estrogens are mainly present in their inactive sulfated form in serum and tissue [23], being estrone-3sulfate an important precursor for the active biological form, E2. As EC has longer half-life than E2, it has been considered a storage form for estrogens [24]. Considering that sulfated estrogens are unable to bind to the estrogen receptors, sulfonation of estrogens results in their inactivation [23]. Therefore, conjugation with sulfate protects cells and tissues from an excess of active estrogens. In addition, sulfate conjugation and removal of the sulfate by 
specific enzymes are important for a balance in the organism [25]. In this context, as EC maximum concentrations were observed after E2 maximum concentrations in the groups that received higher EB concentrations in this study, we suggest that there would be an excess of E2 in the 5- and 10 -mg groups that were sulfated into EC to be inactivated.

When estrogen concentrations of the treated groups were compared with the control group, peak concentrations of EC and E2 were similar, regardless of the EB dose administered. Estrogen concentrations started to decline before LA P4 administration in the 2.5-mg EB group, whereas in the 5- and 10-mg EB groups estrogen concentrations began to decline on the day of LA P4 injection or on the day after, respectively. However, in all treated groups, E2 concentrations were as low as observed in the control group from Day 2 after LA P4 administration onwards which are the usual days in which ET are performed. In this regard, the different doses of EB administered produced similar estrogen concentrations to those found in the control group when comparing maximum estrogen concentrations and after Day 2 of LA P4 injection.

Surprisingly, there was an effect of EB on P4 concentrations, despite the same LA P4 dose given to all treated groups. Higher EB doses led to lower P4 peaks 24 hours after LA P4 administration. In the steroid biosynthetic pathways, cholesterol is converted to pregnenolone by the cholesterol side-chain cleavage enzyme, which in turn can be converted to $\mathrm{P} 4$ through $3 \beta$-hydroxysteroid dehydrogenase and steroid delta-isomerase enzymes. Furthermore, P4 can be converted either to $17-\mathrm{OH}-\mathrm{P} 4$ by the enzyme $17 \alpha$-hydroxylase in the ovaries or to deoxycorticosterone by the 21-hydroxylase enzyme in the adrenals. In the ovaries, androstenedione is formed from 17-OH-P4, followed by conversion into testosterone and to estrogens (including E2) [26]. However, a direct effect of estrogen on P4 after administration of exogenous hormones in mares is still not known.

In cultures of swine granulosa cells, estrogen inhibited total P4 in a time- and dose-dependent fashion [27]. There are two possibilities in which P4 can be inhibited, either by inhibiting conversion of pregnenolone to P4 or accelerating P4 metabolism to its metabolites. The predominant locus of estrogen action was the blockade of pregnenolone's conversion to $\mathrm{P} 4$, rather than accelerated metabolism of $\mathrm{P} 4$ to its metabolites. According to the authors, increasing concentrations of E2 attained in antral follicular fluid during the later stages of follicle maturation could effectively limit the premature secretion of large quantities of P4 before ovulation [27]. We believe that a regulation between estrogen and progesterone could also take place in the mare. Because we provided exogenous P4 to noncyclic mares, we hypothesized that the most likely mechanism by which estrogen would decrease P4 concentrations would be by accelerating P4 metabolism. In this way, we sought to evaluate whether the higher EB doses given to the anestrous mares would generate higher P4 metabolite, namely the 17-OH-P. However, the opposite was observed, the metabolite concentrations accompanied P4 profile, and although concentrations were not statistically different between treated groups, the higher the EB dose administered, the lower the P4 metabolite peak after LA P4 administration. It has been reported that large doses of E2 can decrease
$17 \alpha$-hydroxylase activity in the ovaries of immature hypophysectomized rats [28], thereafter reducing 17-OH-P concentrations. Alternatively, as observed for the control group, we believe that P4 metabolite concentrations in the treated groups may be only the reflection of the normal metabolism of plasma P4.

Considering that accelerated P4 metabolism does not seem to be the mechanism by which high doses of estrogen reduces $\mathrm{P} 4$ concentrations here, the steroidogenesis conversion pathway left is through conversion of P4 to deoxycorticosterone through the enzyme 21-hydroxylase [26]. In pregnant women, estrogen treatment increased conversion of plasma P4 to deoxycorticosterone through regulation of extra-adrenal 21-hydroxylase activity [29]. Therefore, it is very likely that in the groups in which mares received high doses of $\mathrm{EB}$, mainly in the 10-mg EB group, P4 was converted to deoxicorticosterone. This is yet to be determined in future studies.

In conclusion, administration of total doses of $2.5,5$, and $10 \mathrm{mg}$ of EB were effective at promoting maximum uterine edema until treatment with LA P4. However, uterine edema in the 10-mg EB group was not decreased to minimum levels after P4 administration as observed in the control group after ovulation. The three doses induced similar E2 peaks after administration; however, the observation of EC peaks 24 hours after E2 peaks in the 5- and 10-mg groups suggest that an excess of the active form E2 was given which was converted into EC to be inactivated. In addition, administration of $10 \mathrm{mg}$ of EB significantly reduced P4 concentrations 24 hours after LA P4 was given, and we could demonstrate that the mechanism by which high doses of estrogen reduce $\mathrm{P} 4$ concentrations is not by increased $\mathrm{P} 4$ metabolism to 17-OH-P. Therefore, the use of $2.5 \mathrm{mg}$ of EB followed by $1500 \mathrm{mg}$ of LA P4 seems to be a more appropriate regimen to prepare noncyclic mares in our experimental conditions because it produces similar uterine edema and estrogen levels to those observed in cyclic mares, it is a simpler procedure, and it does not interfere with P4 levels after LA P4 administration.

\section{Acknowledgments}

The FAPESP foundation (Fundação de Apoio a Pesquisa e Ensino do Estado de São Paulo) is acknowledged for supporting the first author during the execution of this study through the Research Internship Abroad Fellowship (2014/ 08207-6) in the Department of Animal Science, University of California, Davis, CA, USA. The authors also thank Lillian Sibley (University of California, Davis) for assistance with the hormone assays.

\section{References}

[1] Stroud B. The year 2011 worldwide statistics of embryo transfer in domestic farm animals. Statistics and Data Retrieval Committee Report. IETS Embryo Transfer Newsl 2012;30:16-26.

[2] Silva ESM, Ignácio FS, Pantoja JCF, Puoli Filho JNP, Meira C. Supplementary corpora lutea monitoring allows progestin treatment interruption on day 70 of pregnancy in non-cyclic recipient mares. Anim Reprod Sci 2014;144:122-8.

[3] Rocha Filho AN, Pessôa MA, Gioso MM, Alvarenga MA. Transfer of equine embryos into anovulatory recipients supplemented with short or long acting progesterone. Anim Reprod 2004;1:91-5. 
[4] Hinrichs K, Sertich PL, Cummings MR, Kenney MR. Pregnancy in ovariectomized mares achieved by embryo transfer. Eq Vet J 1985; Suppl 3:74-5.

[5] Hinrichs K, Sertich PL, Kenney RM. Use of altrenogest to prepare ovariectomized mares as embryo transfer recipients. Theriogenology 1986;26:455-60.

[6] McKinnon AO, Squires EL, Carnevale EM, Hermenet MJ. Ovariectomized steroid-treated mares as embryo transfer recipient and as a model to study the role of progestins in pregnancy maintenance. Theriogenology 1988;29:1055-63.

[7] Kaercher F, Kozicki LE, Camargo CE, Weiss RR, Santos IW Muradas PR, et al. Embryo transfer in anovulatory recipient mares treated with estradiol benzoate and long-acting progesterone. J Eq Vet Sci 2013;33:205-9.

[8] Botelho JHV, Pessoa GO, Rocha LGP, Yeste M. Hormone supplementation protocol using estradiol benzoate and long-action progesterone is efficient in maintaining pregnancy of anovulatory recipient mares during autumn transitional phase. Anim Reprod Sci 2015;152:39-43.

[9] Bó GA, Colazo MG, Martínez MF, Kastelic JP, Mapletoft RJ. Sincronizacion de la emergencia de la onda folicular y la ovulacion en animales tratados con progestagenos y diferentes esteres de estradiol. In: Proceedings from the 2 Simposio Internacional de Reprodução Animal Aplicada - biotechnology in bovine reproduction. Londrina; 2006. p. 71-84.

[10] Greco GM, Burlamaqui FLG, Pinna AE, Queiroz FJR, Cunha MPS Brandão FZ. Use of long acting progesterone to acyclic embryo recipient mares. Braz J Anim Sci 2012;41:607-11.

[11] Silva ESM, Pantoja JCF, Puoli Filho JNP, Meira C. Ultrasonography of the conceptus development from days 15 to 60 of pregnancy in non-cyclic recipient mares. Ciência Rural 2015; 45:512-8.

[12] Pinto CRF. Progestagens and progesterone. In: McKinnon AO Squires EL, Vaala WE, Varner DD, editors. Equine reproduction. Second edition. Ames, IA: Blackwell Publishing; 2011. p. 1811-7.

[13] Vanderwall DK. Progesterone. In: McKinnon AO, Squires EL Vaala WE, Varner DD, editors. Equine reproduction. Second edition. Ames, IA: Blackwell Publishing; 2011.p. 1637-41.

[14] Burns PJ, Morrow C, Abraham J. Evaluation of biorelease P4 LA 300 in the mare. In: Proceedings of the 7th International Symposium on Equine Embryo transfer. Cambridge, UK; 2008. p. 82-3.

[15] Greco GM, Avanzi BR, Fioratti EG, Queiroz FJR, Meira C Alvarenga MA. Effect of interrupting the progesterone treatment in pregnant acyclic recipient mares showing supplementary corpora lutea formation. Acta Sci Vet 2008;(Suppl 2):590.
[16] McCue PM, Scoggin CF, Lindholm AFG. Estrus. In: McKinnon AO, Squires EL, Vaala WE, Varner DD, editors. Equine reproduction. Second edition. Ames, IA: Blackwell Publishing; 2011. p. 1716-27.

[17] Parlevliet JM, Pearl CA, Hess MF, Famula TR, Roser JF. Immunolocalization of estrogen and androgen receptors and steroid concentrations in the stallion epididymis. Theriogenology 2006;66:755-65.

[18] Daels PF, Ammon DC, Stabenfeldt GH, Liu IKM, Hughes JP, Lasley BL. Urinary and plasma estrogen conjugates, estradiol and estrone concentrations in non-pregnant and early pregnant mares. Theriogenology 1991;35:1001-17.

[19] Kleinbaum DG, Kupper LL, Nizam A, Muller KE. Applied regression analysis and multivariable methods. Belmont, CA: Duxbury Press; 2007

[20] SAS Institute. SAS/STAT user's guide. Version 9.2. Cary, NC: SAS Institute Inc.; 2011.

[21] Ginther OJ. Reproductive biology of the mare: basic and applied aspects. Second edition. Cross Plains, WI: Equiservices; 1992.

[22] Hayes KEN, Pierson RA, Scraba ST, Ginther OJ. Effects of estrous cycle and season on ultrasonic uterine anatomy in mares. Theriogenology $1985 ; 24: 465-77$.

[23] Secky L, Svoboda M, Klameth L, Bajna E, Hamilton G, Zeillinger R, et al. The sulfatase pathway for estrogen formation: targets for the treatment and diagnosis of hormone-associated tumors. J Drug Deliv 2013;2013:1-13.

[24] Sasano H, Miki Y, Nagasaki S, Suzuki T. In situ estrogen production and its regulation in human breast carcinoma: from endocrinology to intracrinology. Pathol Int 2009;59:777-89.

[25] Purohit A, Woo LWL, Potter BVL. Steroid sulfatase: a pivotal player in estrogen synthesis and metabolism. Mol Cell Endocrinol 2011; 340:154-60.

[26] Stanczyk F. Production, Clearance, and Measurement of Steroid Hormones, Glob Libr Women's Med 2009. http://dx.doi.org/10. 3843/GLOWM.10278. (ISSN: 1756-2228). [accessed 18.05.2015].

[27] Veldhuis JD, Azimi P, Garmey J, Juchter D. Bipotential actions of estrogen and progesterone biosynthesis by ovarian cells. II. Relation of estradiol's stimulatory actions to cholesterol and progestin metabolism in cultured swine granulosa cells. Endocrinology 1985; $117: 1076-83$

[28] Johnson DC, Martin H, Tsai-Morris CH. The in vitro and in vivo effect of estradiol upon the 17 apha-hydroxylase and C17,20-lyase activity in the ovaries of immature hypophysectomized rats. Mol Cell Endocrinol 1984;35:199-204.

[29] MacDonald P, Cutrer S, MacDonald S, Casey ML, Parker CR. Regulation of extra adrenal steroid 21-hydroxylase activity. J Clin Invest $1981 ; 69: 469-78$. 